\title{
Kepatuhan diet dan aktivitas fisik dengan kadar gula darah pada pasien diabetes melitus rawat jalan di RS Harum Sisma Medika Jakarta Timur
}

\author{
Anisa Noviani ${ }^{2,1}$, Adhila Fayasari ${ }^{a}$ \\ aSTIKes Binawan, Jl. Raya Kalibata no.25-30, Cawang, kecamatan Kramat Jati, Jakarta Timur 13630 \\ 1anisanoviani9@gmail.com * \\ *korespondensi penulis
}

\section{Kata kunci: \\ Kadar gula darah puasa}

Kepatuhan diet

Aktivitas fisik
ABSTRAK

Latar belakang : Menurut data WHO jumlah penderita Diabetes Mellitus di Indonesia merupakan urutan ke-4 di dunia tahun 2016. Beberapa faktor yang dapat mempengaruhi kadar gula darah diantaranya kepatuhan terapi diet, kepatuhan minum obat, aktivitas fisik, stres, pengetahuan. Tujuan : Untuk menganalisis hubungan kepatuhan diet dan aktivitas fisik dengan kadar gula darah pada pasien diabetes melitus rawat jalan di RS Harum Sisma Medika. Metode : Desain penelitian adalah cross sectional pada 55 pasien rawat jalan diabetes melitus tipe 2. Instrumen penelitian berupa kuesioner karakteristik, kepatuhan diet DM, aktivitas fisik, dan kadar gula darah puasa. Data dianalisis dengan Kendall's Tau B Correlation. Hasil: Kontrol gula darah yang buruk ditemukan sebesar 69,1\%, dan ketidakpatuhan diet sebesar 16,4\%. Responden yang memiliki kadar gula darah tidak terkontrol sebanyak $38(69,1 \%)$ dan kadar gula darah terkontrol sebanyak 17 (30,9\%). Gambaran kepatuhan diet sebanyak $46(83,6 \%)$ responden patuh terhadap diet dan $9(16,4 \%)$ tidak patuh diet. Kepatuhan diet berpengaruh secara signifikan dengan kadar gula darah $(\mathrm{p}<$ 0,$05 ; \mathrm{r} 0,296$ ) dengan nilai $\mathrm{r} 0,296$. Aktivitas fisik berpengaruh secara signifikan dengan kadar gula darah ( $\mathrm{p}<0,05 ; \mathrm{r}-0.351)$. Kesimpulan : Ada hubungan antara kepatuhan diet dan aktivitas fisik dengan kadar gula darah.

\section{Key words: fasting blood sugar levels}

dietary adherence physical activity

\section{ABSTRACT}

Background: Based on WHO Indonesia is the 4th country with highest diabetics in 2016. Some factors that can affect blood sugar levels were dietary adherence, drug adherence, physical activity, stress, and knowledge. Objectives : To analyze the correlation between dietary adherence and physical activity with blood sugar levels of diabetes mellitus outpatient at Harum Sisma Medika Hospital East Jakarta. Method: This study used cross sectional design of 55 subjects which had type 2 diabetes. Instruments were used in this study were: characteristic questionnaires, dietary adherence, physical activity, fasting blood sugar. Data were analyzed by Kendall's Tau B correlation. Results : Poor blood sugar control was $69.1 \%$, disadherence of diet 16.4\%. Respondents who had uncontrolled blood sugar levels were 38 (69.1\%) and controlled blood sugar levels were 17 (30.9\%). The description of dietary adherence was $46(83,6 \%)$ respondents were adhere and $9(16,4 \%)$ did not adhere to diet. There were significant correlation between dietary adherence and physical activity with blood sugar levels $(p<0,05)$ with $r$ value 0,296 and $-0,351$, respectively.Conclusion: There were significant correlation between dietary adherence and physical activity with blood sugar levels.

This is an open access article under the CC-BY-SAlicense. 


\section{Pendahuluan}

Penyakit degeneratif adalah penyakit kronik yang berkontribusi terhadap kualitas dan produktifitas individu, dan angka penderitanya meningkat cukup pesat dari tahun ke tahun, salah satunya Diabetes Melitus ${ }^{1}$. Diabetes Melitus (DM) merupakan penyakit tidak menular yang prevalensinya cukup tinggi di dunia, sehingga merupakan salah satu masalah kesehatan yang besar. Studi global menunjukan bahwa jumlah penderita DM pada tahun 2014 sebesar 387 juta dan diperkirakan akan meningkat menjadi 592 juta pada tahun $2035^{2}$.

Jumlah penderita Diebetes Melitus (DM) di Indonesia mendapati urutan ke-4 berdasarkan data WHO tahun 20163. Pada tahun 2012-2014, diabtetes mellitus diperkirakan telah menyebabkan 1,5-4,9 juta kematian per tahun dan D setidaknya mempunyai dua kali lipat risiko kematian ${ }^{4}$. Penderita Diabetes Mellitus di Indonesia sebanyak 50\% sadar bahwa mereka mengidap dan 30\% dari angka tersebut sudah melakukan pengobatan rutin ${ }^{5}$

Rumah Sakit Harum Sisma Medika merupakan rumah sakit swasta dengan kategori C. Berdasarkan data di sub bagian rekam medis jumlah penderita diabetes melitus rawat jalan terus mengalami peningkatan dan termasuk dalam 10 besar penyakit rawat jalan dan menempati urutan ke-3. Pada tahun 2015 jumlah pasien rawat jalan diabetes melitus terdapat 1.223 pasien dan mengalami peningkatan pada tahun 2016 sebanyak 1.536 pasien. Jumlah pasien diabetes melitus rawat jalan pada bulan Juni 2017 terdapat 202 orang, bulan Juli 2017 terdapat 266 orang, dan pada bulan Agustus 2017 terdapat 289 pasien. Data tersebut menandakan adanya peningkatan jumlah kasus diabetes melitus setiap bulannya ${ }^{6}$.

Penatalaksanaan DM meliputi edukasi, terapi medis/gizi, latihan jasmani dan farmakologi. Salah satu terapi utama pada penderita DM adalah pemberian diet dimana penderita direkomendasikan untuk melaksanakan diet secara tepat agar tidak terjadi komplikasi dan terkendalinya kadar gula darah ${ }^{7,8}$.

Pengendalian kadar gula darah pada pasien DM diperlukan agar tidak menimbulkan komplikasi kronik akibat gula darah yang tidak terkontrol. Hal ini salah satunya dipengaruhi oleh terapi diet yang berperan penting untuk mencapai keberhasilan terapi ${ }^{9}$. Penelitian di RSU Bethesda GMIM Tomohon, menyebutkan bahwa kepatuhan pengaturan diet berhubungan dengan kadar glukosa darah pada pasien diabets melitus ${ }^{10}$.

Selain itu faktor lain adalah aktivitas fisik. Menurut penelitian yang dilakukan yang lain terdapat hubungan antara aktivitas fisik dengan kadar glukosa darah pada pasien diabetes melitus. Bahwa pasien dengan kebiasaan aktivitas fisik sesuai anjuran sebagian besar mempunyai kadar glukosa darah sewaktu yang terkontrol ${ }^{11}$.

Berdasarkan uraian di atas melatarbelakangi peneliti untuk melakukan penelitian tentang Hubungan Kepatuhan Diet dan Aktivitas Fisik Dengan Kadar Gula Darah Pada Pasien Diabetes Melitus Rawat Jalan Di RS Harum Sisma Medika.

\section{Metode}

Jenis penelitian yang dilakukan bersifat non eksperimental yang merupakan studi observasional dengan melakukan pendekatan cross sectional. Penelitian ini dilakukan untuk menganalisis hubungan yang terkait antara kepatuhan diet dan aktitivitas fisik dengan kadar gula darah pada pasien diabetes melitus.

Sasaran penelitian ini adalah pasien dengan diagnosa diabetes melitus tipe 2 rawat jalan di Rumah Sakit Harum Sisma Medika yang masuk dalam kriteria pasien rawat jalan laki-laki 
dan perempuan dengan diagnosa diabetes melitus tipe 2 berusia $>18$ tahun, minimal sudah pernah sekali mendapatkan edukasi gizi, pasien DM yang memiliki pemeriksaan kadar gula darah puasa (GDP) maksimal 2 minggu terakhir, dan bersedia untuk dijadikan responden atau sampel penelitian apabila pasien DM dengan komplikasi gangren, jantung, stroke (lemah anggota gerak), komplikasi penyakit lainnya (gangguan fungsi ginjal, hiperurisemia, dislipidemia) maka tidak termasuk ke dalam sampel penelitian. Pengambilan sampel menggunakan metode purposive sampling dan perhitungan menggunakan perhitungan analis korelatif. Sampel pada penelitian ini ditambah 10\% dari total sampel untuk mencegah terjadinya sampel drop out.

Instrumen yang digunakan pada penelitian ini adalah dengan kuesioner. Kuesioner merupakan alat ukur penelitian yang perlu diuji coba terlebih dahulu sebelum digunakan, hal ini berguna untuk menilai layak tidaknya kuesioner tersebut dijadikan sebagai instrumen penelitian nantinya. Semua kuesioner yang telah diisi oleh reponden kemudian diperiksa dengan teliti setelah itu diberi nomor, disusun secara berurutan mulai dari responden pertama hingga terakhir kemudian di olah menggunakan program spss dengan Uji Kendall's Tau B. Penelitian ini sudah terdaftar pada komisi etik dengan nomor etik 023/EP/KES/STIKES-BIN/VI/2018

\section{Hasil dan Pembahasan}

Karakteristik responden pada penelitian ini diantaranya usia, jenis kelamin, pendidikan dan riwayat keluarga dengan diabetes melitus yang ditunjukkan pada Tabel 1 .

Berdasarkan tabel 1, diketahui bahwa responden penelitian ini hampir separuhnya berusia dewasa lanjut yaitu $58,2 \%$ dengan lebih dari separuhnya berjenis kelamin perempuan $(52,7 \%)$. Responden dalam penelitian ini juga lebih dari separuhnya berpendidikan tinggi $(52,7 \%)$ dan sebagian besar memiliki riwayat keluarga diabetes melitus (72,5\%). Kadar gula darah puasa (GDP) yang tidak terkontrol $(69,1 \%)$ tetapi sebagian besar patuh terhadap diet $(83,6 \%)$ dan sebagian besar memiliki aktivitas fisik yang sedang $(70,9 \%)$.

Berdasarkan tabel 2 dapat diketahui bahwa mayoritas responden tidak patuh terhadap diet memiliki kadar gula darah yang tidak terkontrol, sebagian besar responden patuh terhadap diet memiliki kadar gula darah tidak terkontrol (63\%). Dari hasil analisis hubungan antara kepatuhan diet dengan kadar gula darah didapatkan $p$ value $0,001(p<0,05)$ yang berarti bahwa secara statistik terdapat hubungan yang bermakna. Adapun nilai $r$ yang diperoleh dari analisis ini adalah 0,296 yang berarti terdapat hubungan positif yang lemah. Hubungan positif bermakna bahwa semakin tinggi tingkat kepatuhan responden semakin baik kadar gula darah.

Penelitian ini sejakan dengan hasil penelitian di Pontianak yang menyebutkan bahwa kepatuhan diet pada penderita DM berpengaruh terhadap penurunan kadar gula darah puasa secara signifikan ${ }^{13}$.

Adapun faktor kepatuhan diet yang tepat belum tentu dapat menjamin terkendalinya kadar gula darah pada penderita DM. Kadar gula darah dipengaruhi juga oleh faktor lain, yaitu faktor karakteristik (usia, jenis kelamin), pengetahuan, dukungan keluarga, merokok, kepatuhan terapi obat, aktivitas fisik, stres, obesitas, hipertensi, dan lama menderita $\mathrm{DM}^{14}$. Pengetahuan, dukungan keluarga, kepatuhan terapi obat dan asupan lemak berpengaruh secara langsung terhadap stabilitas kadar gula daraha pada penderita $\mathrm{DM}^{15}$.

Pada variabel aktivitas fisik hampir separuh dari responden yang memiliki aktivitas ringan memiliki kadar gula darah yang terkontrol, dan sebagian besar responden dengan aktivitas fisik sedang 
memiliki kadar gula darah yang tidak terkontrol (79,5\%). Dari hasil analisis hubungan aktivitas fisik dengan kadar gula darah ( $\mathrm{p}<0,05 ; \mathrm{r}-0,351$ ), walaupun nilai $\mathrm{r}$ yang diperoleh dari analisis ini adalah $-0,351$ yang berarti terdapat hubungan negatif yang lemah. Hubungan negatif yang lemah bermakna semakin tinggi tingkat aktivitas fisik atau pada penelitian ini dalam kategori sedang, semakin baik kadar gula darah atau terkontrol.

Tabel 1. Distribusi Karakteristik Responden

\begin{tabular}{lcc}
\hline \multicolumn{1}{c}{ Karakteristik } & Jumlah & Persentase (\%) \\
\hline Usia & & \\
Dewasa muda & 17 & 30,9 \\
$\quad$ Dewasa lanjut & 32 & 58,2 \\
$\quad$ Lansia & 6 & 10,9 \\
Jenis Kelamin & & \\
$\quad$ Perempuan & 29 & 52,7 \\
$\quad$ Laki-laki & 26 & 47,3 \\
Pendidikan & & \\
$\quad$ Rendah & 3 & 5,5 \\
$\quad$ Sedang & 23 & 41,8 \\
$\quad$ Tinggi & 29 & 52,7 \\
Riwayat Keluarga DM & & \\
$\quad$ Ada riwayat & 40 & 72,7 \\
$\quad$ Tidak ada riwayat & 15 & 27,3 \\
Kadar GDP & & \\
$\quad$ Tidak terkontrol & 38 & 69,1 \\
$\quad$ Terkontrol & 17 & 30,9 \\
Kepatuhan Diet & & \\
$\quad$ Tidak patuh & 9 & 16,4 \\
$\quad$ Patuh & 46 & 83,6 \\
Aktivitas Fisik & & \\
$\quad$ Ringan & 16 & 29,1 \\
$\quad$ Sedang & 39 & 70,9 \\
\hline
\end{tabular}

Hasil studi ini sejalan dengan penelitian di Surabaya yang menyebutkan bahwa aktivitas fisik berkorelasi dengan kadar gula darah puasa responden penderita Diabetes Melitus tipe 2 $(\mathrm{p}<0,05)^{16}$. Aktivitas fisik yang rendah pada penderita DM cenderung lebih banyak yang mengalami kadar gula darah puasa tinggi (76,9\%). Hasil uji statistik dengan Spearman's rho menunjukkan hasil nilai $\mathrm{p}=0,000$ yang mana hasil tersebut lebih kecil dari alfa $(0,01)$. Namun terdapat perbedaan hasil yang diteliti pada penelitian yang dilakukan ini lebih banyak responden dengan aktivitas fisik sedang 31 responden $(79,5 \%)$ memiliki kadar gula darah yang tidak terkontrol. Dapat disimpulkan bahwa terdapat faktor lain yang menyebabkan kadar gula darah puasa tidak terkontrol.

Dari penelitian ini ditemukan bahwa variabel kepatuhan diet dan aktivitas fisik memiliki hubungan yang bermakna dengan kadar gula darah, puasa pada pasien diabetes melitus, namun ada variabel lain yang peneliti tidak teliti yang berpengaruh dengan kadar gula darah diantaranya tingkat stress, keteraturan minum obat, dan tingkat pengetahuan. 
Tabel 2. Analisis Bivariat Hubungan Kepatuhan Diet dan Aktifitas Fisik dengan Kadar Gula

\begin{tabular}{lcccccccc}
\hline \multirow{2}{*}{ Variabel } & \multicolumn{2}{c}{$\begin{array}{c}\text { Tidak } \\
\text { terkontrol }\end{array}$} & \multicolumn{2}{c}{ Terkontrol } & Total & \% & $\begin{array}{c}\mathbf{P} \\
\text { value }\end{array}$ & $\mathbf{r}$ \\
\cline { 2 - 5 } & $\mathbf{n}$ & $\mathbf{\%}$ & $\mathbf{N}$ & $\mathbf{\%}$ & & & & \\
\hline $\begin{array}{l}\text { Kepatuhan diet } \\
\text { Tidak patuh }\end{array}$ & 9 & 100 & 0 & 0 & 9 & 100 & 0,030 & 0,296 \\
$\begin{array}{l}\text { Patuh } \\
\text { Aktivitas fisik }\end{array}$ & 29 & 63 & 17 & 37 & 46 & 100 & & \\
$\begin{array}{l}\text { Ringan } \\
\text { Sedang }\end{array}$ & 7 & 43,8 & 9 & 56,2 & 16 & 100 & & \\
\hline
\end{tabular}

Tingkat stress berhubungan dengan tingat kadar gula darah pada penderita DM di Puskesmas Puskesmas Peterongan Kabupaten Jombang (p 0,001) ${ }^{17}$. Dalam keadaan stress, dapat terjadi perubahan pola makan dan penggunaan obat yang berakibat pada tidak terkontrolnya kadar gula darah. Selain itu peningkatan hormon "stres" akan meningkatkan kadar glukosa darah, bila asupan makanan dan pemberian insulin tidak terkontrol. Keadaan ini akan menimbulkan hiperglikemia atau bahkan hipoglikemia. Sehingga apabila penderita DM mengalami stres, maka akan berpengaruh terhadap kadar gula darahnya ${ }^{17}$.

Hasil penelitian di RSUD Arjawinangun menunjukan bahwa kadar glukosa darah dipengaruhi oleh keteraturan minum obat $(\mathrm{p}=0,032)^{18}$. Ketidakakontrolan kadar gula darah tidak terkontrol mempunyai asosiasi positif dengan kadar gula darah pasien $(p<0,05)$. Ketidakkontrolan kadar gula darah dapat dikarenakan oleh pengetahuan yang kurang. Proporsi kadar gula tidak terkontrol lebih banyak pada pasien dengan pengetahuan kurang $(90,3 \%)^{19}$.

Dari analisa setiap pernyataan positif dan negatif pada kategori jadwal, jumlah, dan jenis makanan yang dijawab oleh 9 orang responden yang tidak patuh terhadap diet dapat disimpulkan dari segi :pernyataan Jadwal, Jumlah, dan Jenis makanan

Jadwal. Lebih dari separuh responden (64,8\%) makan utama kurang dari 3 kali dalam sehari dengan jadwal makan yang kurang teratur dan jarang konsumsi makanan selingan atau camilan. Hal ini menandakan pola pikir responden yang belum dapat menyesuaikan jadwal makan teratur dalam kehidupan sehari-harinya sesuai anjuran tenaga kesehatan.

Jumlah. Lebih dari separuh responden (72,5\%) menjawab jarang mengkonsumsi nasi, lauk pauk, sayuran, dan buah sesuai ukuran diet dari petugas kesehatan. Responden kurang membatasi konsumsi makanan dengan karbohidrat tinggi seperti roti, kentang, dan umbiumbian. Responden jarang konsumsi lauk pauk sesuai ukuran diet kira-kira 1 potong sedang dalam sekali makan, dan juga jarang konsumsi sayur kurang lebih 100 gram (1 gls) dalam sekali waktu makan. Hal ini menandakan pola pikir responden yang belum dapat mematuhi penatalaksanaan terapi nutrisi/diet yang mengarah pada gizi seimbang dan pola pikir makan dengan menu yang seadanya saja tanpa memperhatikan nilai gizi dari asupan makan tersebut.

Lebih dari separuh responden (67\%) sering mengkonsumsi nasi dengan ukuran atau porsi yang sama setiap waktu makan pagi, makan siang, dan makan malam. Hal ini menandakan pola pikir responden yang belum dapat menerima dan mengaplikasikan anjuran diet dari tenaga kesehatan terkait asupan energi dan zat gizi serta pola pikir 
responden yang masih menganggap sama atau menyamaratakan porsi nasi di setiap waktu makan pagi, siang, dan malam.

Jenis makanan. Pada umumnya responden sudah baik dalam menjawab setiap pernyataan dari kategori jenis makanan, namun sebanyak $56 \%$ responden yang tidak patuh diet menjawab jarang atau minimal dilakukan 1-3 kali dalam seminggu atas pernyataan saya suka makanan yang asin seperti ikan asin, telur asin, makanan diawetkan. Hal ini menandakan pola pikir responden yang kurang baik dalam pemilihan jenis makanan dan jika dikonsumsi dalam jumlah yang berlebih.

\section{Kesimpulan dan Saran}

Kepatuhan diet dan aktivitas fisik berpengaruh signifikan dengan kadar gula darah puasa pasien diabetes melitus rawat jalan di RS Harum Sisma Medika. Disarankan agar lebih menggali informasi dari pasien dan keluarga dalam melakukan asesmen atau pengkajian gizi untuk menilai faktor - faktor lainnya yang berkaitan dengan kadar gula darah puasa.

Adapun upaya untuk mengendalikan kada gula darah pada pasien Diabetes Melitus adalah dengan pengelolaan program rutin dengan bekerjasama dengan tenaga medis lain sebagai contoh edukasi gizi terkait kepatuhan jadwal makan dan jumlah dari setiap jenis makanan yang dikonsumsi, penyuluhan kesehatan terkait diabetes melitus, dan senam sehat diabetes.

\section{Reference}

1. Teguh, Susanto. 2013. Diabetes Deteksi, Pencegahan, Pengobatan. Yogyakarta : Buku Pintar. Dalam: Vinti, Dwi. 2015. Hubungan Pengetahuan Dan Kepatuhan Diet Dengan Kadar Gula Darha Pada Pasien Diabetes Melitus di Poliklinik Khusus Penyakit Dalam RSUP DR.M.Djamil Padang Tahun 2015. KTI Poltekkes Padang.

2. International Diabetes Federation. 2014. Diabetes. Diakses tanggal 26 November 2017

3. http://www.searo.who.int/indonesia/topics/8-whd2016-diabetes-facts-and-numbersindonesian.pdf

4. WHO. 2013.Diabetes. www.who.int. Diakses pada tanggal 26 November 2017

5. Soegondo S. \& Sukardji K. 2008. Hidup Secara Mandiri dengan Diabetes Mellitus Kencing Manis Sakit Gula. Jakarta: FKUI

6. Rumah Sakit Harum Sisma Medika. 2017. Data Laporan Bulanan Rumah Sakit Sisma Medika Tahun 2017. RS Harum Sisma Medika

7. PERKENI. 2015. Konsensus Pengelolaan dan Pencegahan Diabetes Melitus Tipe 2 di Indonesia. Jakarta

8. Arsana.2011.Dalam: Vinti, Dwi. 2015. Hubungan Pengetahuan Dan Kepatuhan Diet Dengan Kadar Gula Darha Pada Pasien Diabetes Melitus di Poliklinik Khusus Penyakit Dalam RSUP DR.M.Djamil Padang Tahun 2015. KTI Poltekkes Padang.

9. Juniarti,Citra., Tasa, Hamzah., Semana, Akuilina. 2014. Hubungan Pengetahuan dengan Kepatuhan Diet pada Penderita Diabetes Melitus yang dirawat di RSUD Labuang Baji Makassar : Jurnal Volume 4 Nomor 1 Stikes Nani Hasannudin.

10. Tangka, Jon W., Wiyono., Wati, Anastasya T. Hubungan Kepatuhan Pengaturan Diet Dengan Kadar Glukosa Darah Pada Pasien Diabetes Melitus : Buletin Sariputra, Februari 2015 Vol. 5

11. Setyawan, Septa dan Sono. 2015. Hubungan Aktivitas Fisik Dengan Kadar Glukosa Darah Sewaktu Pada Pasien Diabetes Melitus : Jurnal Keperawatan, Volume XI, No. 1, April 2015 
12. Almatsier, Sunita. 2011. Prinsip Dasar Ilmu Gizi. Jakarta : PT. Gramedia. Pustaka

13. Astari, R. 2016. Hubungan Antara Kepatuhan Terapi Diet Dan Kadar Gula Darah Puasa Pada Penderita Diabetes Melitus Tipe 2 Di Wilayah Kerja Puskesmas Purnama Pontianak. Pontianak (Naskah Publikasi) Universitas Tanjungpura : Pontianak

14. Rusmina,D, 2010, Hubungan Kepatuhan dalam Menjalankan Diet dengan Gula Darah Terkontrol pada Pasien Diabetes Melitus di Poliklinik Penyakit Dalam RSAL dr.Mintohardjo Jakarta Pusat, Jakarta. (Skripsi). Dalam: Astari, R. 2016. Hubungan Antara Kepatuhan Terapi Diet Dan Kadar Gula Darah Puasa Pada Penderita Diabetes Melitus Tipe 2 Di Wilayah Kerja Puskesmas Purnama Pontianak. (Naskah Publikasi). Universitas Tanjungpura : Pontianak

15. Astuti, Catur Mei dan Setiarini, A. 2013. Faktor-Faktor yang Berhubungan dengan Pengendalian Kadar Glukosa Darah Pasien Diabetes Melitus Tipe 2 Rawat Jalan di Poliklinik Penyakit Dalam RSJ Prof. Dr. Soerojo Magelang Tahun 2013 :Jurnal Universitas Indonesia

16. Nurayati L, Adriani M, 2017. Hubungan Aktivitas Fisik dengan Kadar Gula Darah Puasa Penderita Diabetes Melitus Tipe 2. Surabaya. Amerta Nutr

17. Irfan, M dan Wibowo, H. 2015. Hubungan Tingkat Stres Dengan Kadar Gula Darah Pada Penderita Diabetes Melitus (DM) di Puskesmas Peterongan Kabupaten Jombang : Jurnal Ilmiah Keperawatan Volume 1 No. 2 September 2015

18. Anani, S., Udiyono, A., Ginanjar, P. 2012. Hubungan Antara Perilaku Pengendalian Diabetes dan Kadar Glukosa Darah Pasien Rawat Jalan Diabetes Melitus (Studi Kasus di RSUD Arjawinangun Kabupaten Cirebon). Jurnal Kesehatan Masyarakat, Volume 1, Nomor 2, Tahun 2012, Halaman $466-478$

19. Vinti, Dwi. 2015. Hubungan Pengetahuan Dan Kepatuhan Diet Dengan Kadar Gula Darah Pada Pasien Diabetes Melitus di Poliklinik Khusus Penyakit Dalam RSUP DR.M.Djamil Padang Tahun 2015. KTI Poltekkes Padang. 